\title{
Colorectal cancer incidence and clinicopathological features in northern Tunisia 2007-2009
}

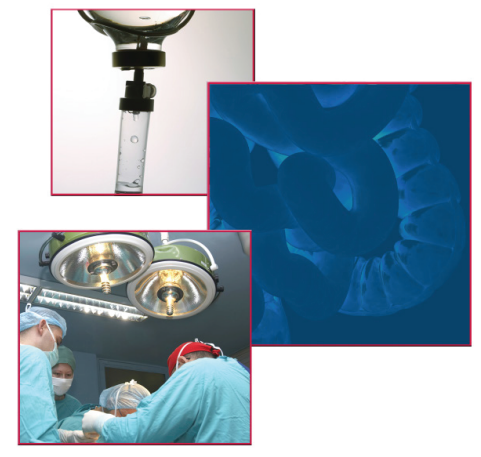

\author{
Houyem Khiari*,1 \& Mohamed Hsairi ${ }^{1}$ \\ ${ }^{1}$ Department of Epidemiology, Salah Azaiez Institute of Tunis, Tunis, Tunisia \\ *Author for correspondence: Khiari_hyem@yahoo.fr
}

\section{Practice points}

- The aim of this study was to determine the age-standardized incidence rate (ASR) of colorectal cancer (CRC) for the period 2007-2009, to describe some CRC epidemiological characteristics and to analyze the clinicopathological features of the CRC in northern Tunisia.

- ASR of colorectal cancer during the period 2007-2009 was a bit higher than the 2004-2006 one.

- The distribution of CRC cases and standardized incidence rates by age, gender, sub site, histological type and governorates were described and analysed in northern Tunisia.

- Incidence standardized rate of CRC during the 2007-2009 period was 12.4 cases/100,000 (13.6 against 11.1 respectively in men and women) in the northern region of Tunisia.

- The mean age at diagnosis was $60 \pm 15$ years and the gender ratio was 1.2 .

- Adenocarcinoma was the most common histological type observed.

- The most affected subsites were respectively the rectum, distal then proximal colon.

Colorectalcancer (CRC) is the third most commonly diagnosed cancer worldwide. The aim of this study was to determine CRC incidence and to describe clinicopathological features in north Tunisia for the period 2007-2009. The North Tunisia Cancer Registry was the source of data for the identification of patients. The age-standardized incidence rates (ASRs) were respectively 13.6 cases $(7.5 / 100,000$ for colon cancer and 6.2 for rectal cancer) and 11.1 cases (6.5/100,000 for colon cancer and 4.4 for rectal cancer) per 100,000 among male and female. The ASR varied widely by regions in northern Tunisia. The most common site in colon cancer was the distal colon comparing to the proximal one ( 49.0 and $29.9 \%$ respectively). Adenocarcinoma was the most common histological type. CRC screening should be strengthened in Tunisia to achieve a reduction of CRC incidence and mortality.

First draft submitted: 27 September 2017; Accepted for publication: 30 November 2017; Published online: 21 February 2018

Keywords: colorectal cancer • epidemiology $\bullet$ Tunisia

Colorectal cancer (CRC) is a major cause of morbidity and mortality worldwide. It is the third most common cancer with 1.4 million new cases in 2012 and the fourth-leading cause of cancer with 693,333 deaths each year in the world [1-3]. However, there is a large variation in CRC incidences in more developed versus less developed countries. Indeed, the highest rates were observed in the USA, Canada, Australia, New Zealand and Europe (especially in Czech Republic and Slovakia) where the age-standardized incidence rate (ASR) was 44.8 in men and 32.2 per 100,000 in women; while India, Egypt and central-west Africa show the lowest rates with an ASR of 4.5 and 3.8 per 100,000 in men and women, respectively [4-8]. These differences are due to disparities of several risk factors, including obesity, eating habits and lack of physical activity, but also to the efficacy of prevention policies [9-14]. In Tunisia, CRC is also a serious health problem. It is the second most common cancer in terms of incidence in women and the third in men. According to estimations of the International Agency of Research on Cancer (GLOBOCAN 2012), the ASR was 10.9 per 100,000 which is a low-to-medium rate (11.9 and 10 per 100,000, respectively, among men and women) [15]. These cancers were included in the screening program as pilot experiences in cancer plans 2010-2014 and 2015-2019 [16]. 


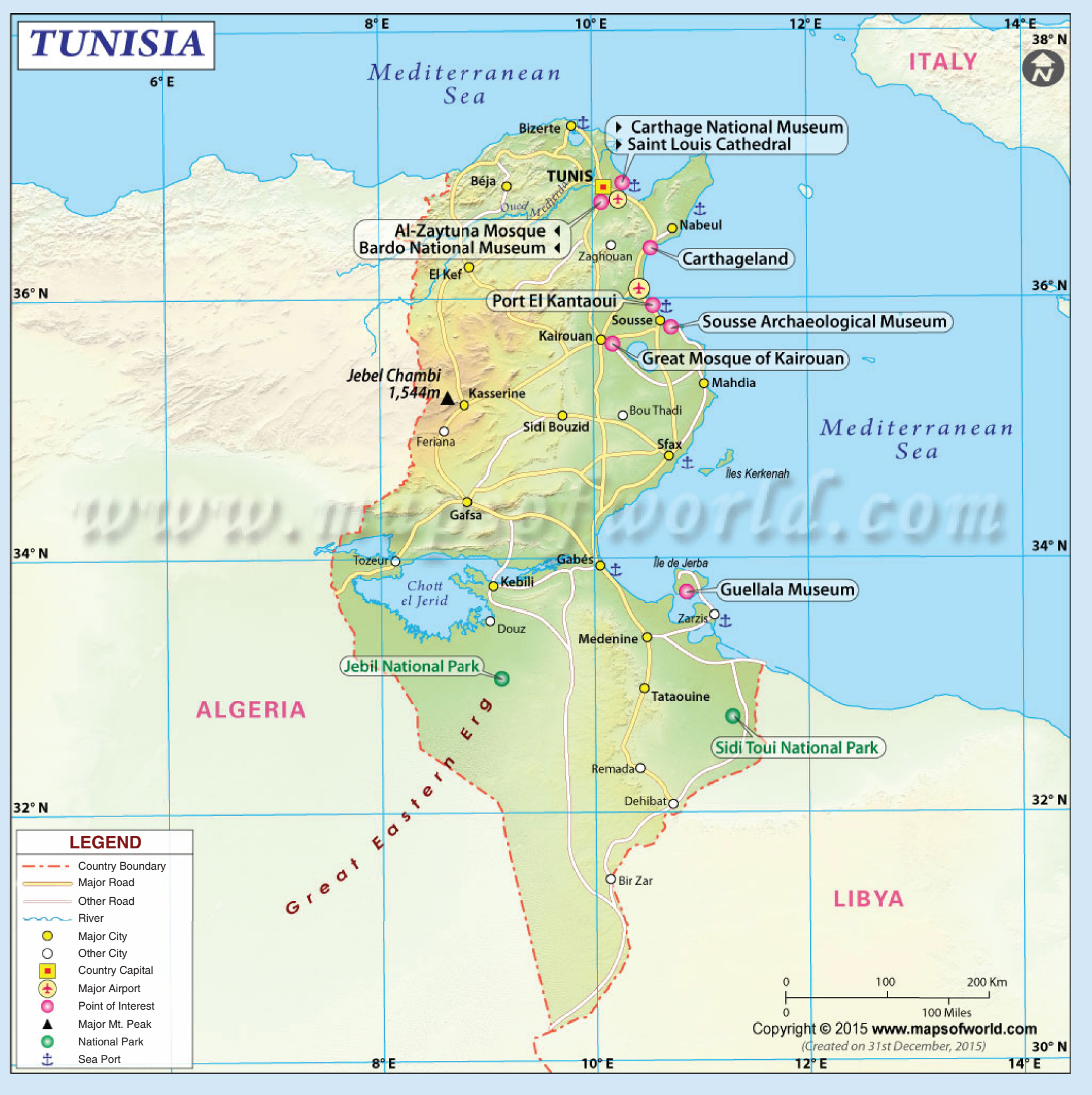

Figure 1. Country of Tunisia: administrative subdivision.

The incidence data on cancers in Tunisia are provided by three regional registries that were implemented in 1998: one for the northern region, the second one for the governorate of Sousse in the center and the last one for the governorate of Sfax in the south. The northern cancer registry covers 11 governorates involving the district of Tunis (Tunis, Ben Arous, Ariana and Mannouba), the north east (Zaghouan, Bizerte and Nabeul) and the north west (Béja, Kef, Siliana and Jendouba; Figure 1) [17]. This northern-region population shelters 5,035,000 habitants which represents around the half of the Tunisian population [18]. In Tunisia, epidemiological data on CRC are rare; the latest incidence data are for the periods 2004-2006 and 2003-2007, for the northern and the central regions, respectively [17,19-21]. The aim of this study was to determine the ASR for the period 2007-2009, to describe some 
Table 1. Distribution of colorectal standardized incidence rates by site and gender in northern Tunisia (2007-2009).

\begin{tabular}{|c|c|c|c|c|c|c|c|c|c|}
\hline \multirow{2}{*}{$\begin{array}{l}\text { Number and } \\
\text { ASR }\end{array}$} & \multicolumn{3}{|c|}{ Colon cancer } & \multicolumn{3}{|c|}{ Rectal cancer } & \multicolumn{3}{|c|}{ Colorectal cancer } \\
\hline & Men & Women & Both & Men & Women & Both & Men & Women & Both \\
\hline Number & 524 & 473 & 997 & 439 & 319 & 758 & 964 & 791 & 1755 \\
\hline $\begin{array}{l}\text { ASR (per } \\
100,000)\end{array}$ & 7.5 & 6.5 & 7.1 & 6.2 & 4.4 & 5.3 & 13.7 & 10.9 & 12.4 \\
\hline
\end{tabular}

ASR: Age-standardized incidence rate.

epidemiological characteristics of CRC in northern Tunisia and to analyze the clinicopathological features of the CRC.

\section{Methods}

Demographic data were provided by the National Institute of Statistics [18] concerning the distribution of the population of northern Tunisia according to years, depending on age classes (5-year intervals for each class), according to sex and governorates (Figure 1). The North Tunisia Cancer Registry was the source of data for the identification of patients for this study. The main data sources were medical ones of both public and private sectors in the corresponding governorates. Contractual doctors visited all sources to collect data using a standard data collection sheet. This record includes three parts: sociodemographic characteristics of patients, identification of the tumor and evolution of the disease. Regarding codification of tumors, the International Classification of Diseases for Oncology (ICD-O) was used (ICD-O-1 during the period 1994-2003 and ICD-O-3 since 2004). CRC was divided into subsites: proximal colon that includes the cecum (C18.0), ascending colon (C18.2), the hepatic flexure of the colon (C18.3), transverse colon (C18.4) and the splenic flexure of the colon (C18.5); distal colon includes descending colon (C18.6) and sigmoid colon (C18.7); and the rectum includes the rectosigmoid junction (C19) and the rectum (C20). Data were entered using Epi Info software (version 6). The checks of the data entered are performed periodically, by following some steps: careful search of duplicates; verification of the degree of filling the mandatory variables (gender, age, place of residence); verification of the validity of codes of tumors and the search for incoherencies between gender, age and nature of the tumor, histological type and site. To determine the incidence of CRC, we have calculated crude and standardized rates using the direct method of standardization. Data were analyzed using SPSS version 17. Categorical data were described by calculating percentages and quantitative data through the calculation of means and standard deviations.

\section{Results}

Incidence of CRC

During the 2007-2009 period, 1755 new cases of CRC were recorded in the northern region of Tunisia (964 cases among men and 791 cases among women, gender ratio $=1.2$ ). Table 1 summarizes the distribution of incidence by site (colon or rectum) and gender. The standardized incidence rates were respectively 13.6 cases $(7.5 / 100,000$ for colon cancer and 6.2/100,000 for rectal cancer) and 11.1 cases $(6.5 / 100,000$ for colon cancer and 4.4 for rectal cancer) per 100,000, respectively, for male and female (Table 1$)$.

\section{Age distribution}

The mean age at diagnosis of CRC was $60 \pm 15$ years (61.4 \pm 14 years in men and $58.5 \pm 15$ years in women). The highest proportions were observed for the age groups 65-69 and 70-74 years, 13.8 and 13.7\%, respectively (Figure 2).

For both genders, and for colon and rectum cancer, incidence rates increased by age (Figures $3 \& 4$ ).

\section{Distribution by subsite $\&$ gender}

Figure 5 shows that the most common site in colon cancer was the distal colon comparing to the proximal one (49.0 and $29.9 \%$, respectively). The sigmoid colon showed most cases of distal colon with 28.8\% (Table 2). Figure 6 illustrates that the most common site within female gender was distal colon while it was the rectum within males.

\section{Distribution by histological type}

Adenocarcinoma was the most common histological type, which represented 86.3 and $82.0 \%$ for men and women, respectively (Table 3 ). 


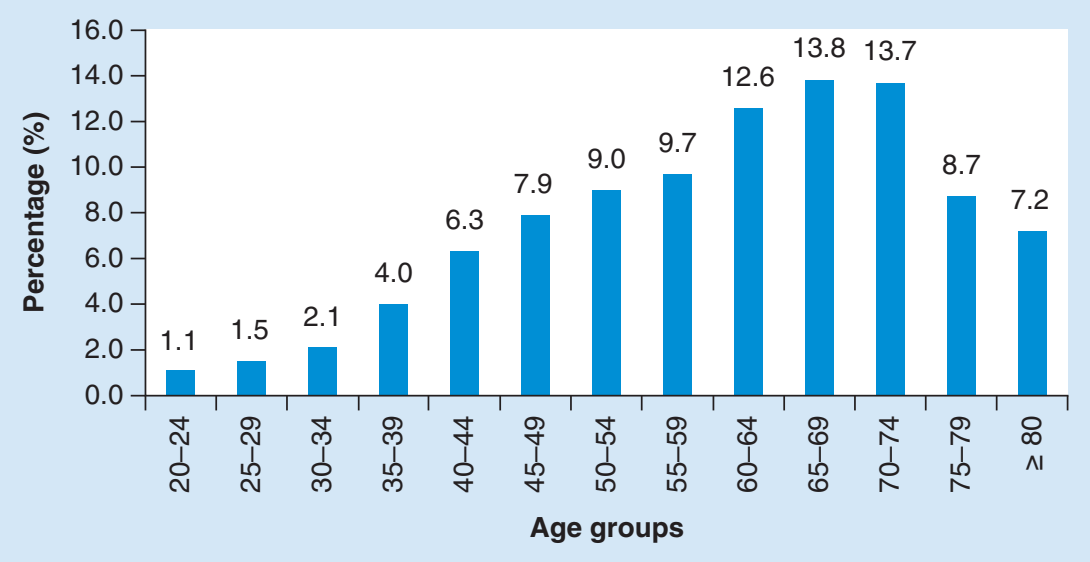

Figure 2. Case distribution by age group.

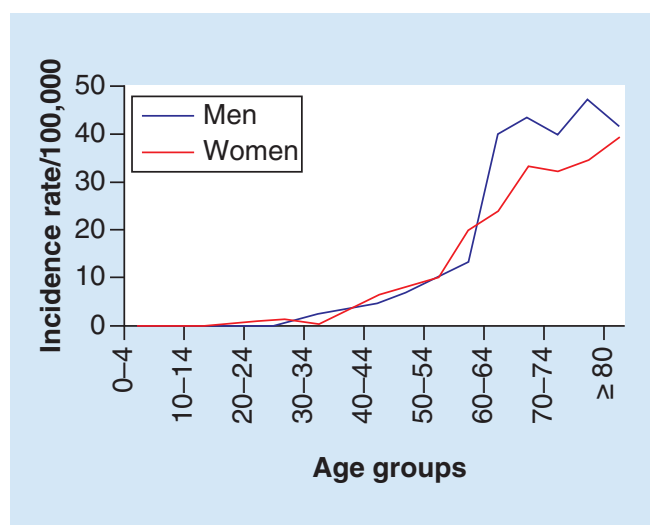

Figure 3. Colon cancer: incidence by age and gender.

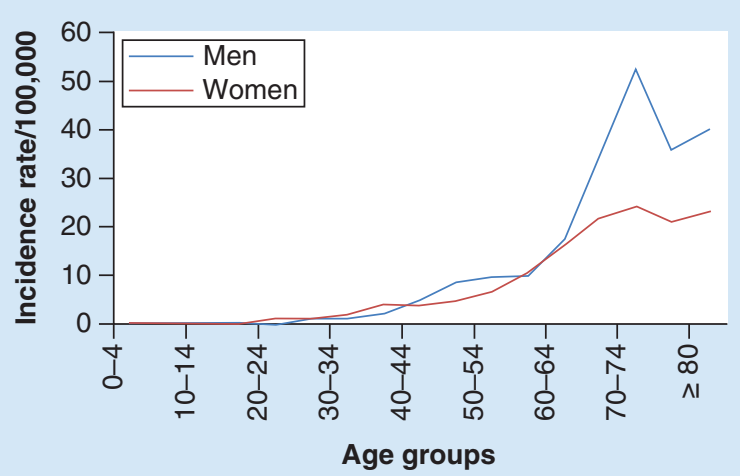

Figure 4. Rectal cancer: incidence by age and gender.

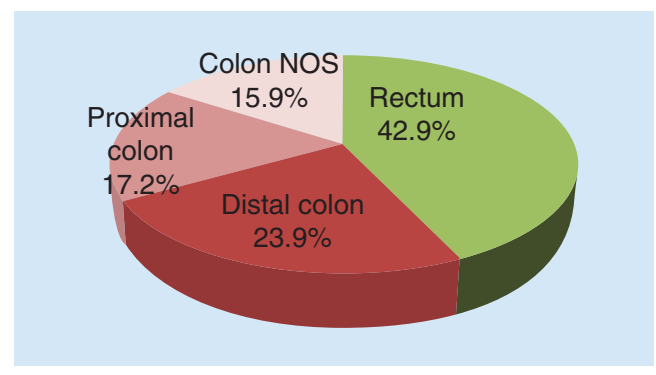

Figure 5. Proportion of cases by subsite.

NOS: Not otherwise specified. 
Table 2. Number and proportion of cases by gender and anatomic site.

\begin{tabular}{|c|c|c|c|c|c|c|}
\hline \multirow[t]{2}{*}{ Site } & \multicolumn{2}{|c|}{ Men } & \multicolumn{2}{|c|}{ Women } & \multicolumn{2}{|c|}{ Total } \\
\hline & n & $\%$ & n & $\%$ & n & $\%$ \\
\hline Cecum & 58 & 11.0 & 31 & 6.6 & 89 & 8.9 \\
\hline Appendix & 8 & 1.5 & 26 & 5.5 & 34 & 3.4 \\
\hline Ascendant colon & 75 & 14.3 & 51 & 10.8 & 126 & 12.6 \\
\hline $\begin{array}{l}\text { Hepatic flexure of the } \\
\text { colon }\end{array}$ & 10 & 1.9 & 7 & 1.5 & 17 & 1.7 \\
\hline Transverse colon & 8 & 1.5 & 14 & 3.0 & 22 & 2.2 \\
\hline $\begin{array}{l}\text { Splenic flexure of the } \\
\text { colon }\end{array}$ & 8 & 1.5 & 6 & 1.3 & 14 & 1.4 \\
\hline Proximal colon $\ddagger$ & 167 & 31.8 & 135 & 28.6 & 302 & 30.3 \\
\hline Descendant colon & 51 & 9.7 & 61 & 12.9 & 112 & 11.2 \\
\hline Sigmoid colon & 149 & 28.4 & 138 & 29.2 & 287 & 28.8 \\
\hline $\begin{array}{l}\text { Adjoining lesion of } \\
\text { the colon }\end{array}$ & 9 & 1.7 & 8 & 1.7 & 17 & 1.7 \\
\hline Distal colon $\S$ & 209 & 39.8 & 207 & 43.9 & 416 & 41.7 \\
\hline Colon NOS & 149 & 28.4 & 130 & 27.5 & 279 & 28.0 \\
\hline \multicolumn{7}{|c|}{$\begin{array}{l}\ddagger \text { Proximal colon is composed from the caecum, appendix, ascendant colon, hepatic flexure of the colon, transverse colon and the splenic flexure of the colon. } \\
\text { § Distal colon is composed from the descendant colon and the sigmoid colon. } \\
\text { NOS: Not otherwise specified. }\end{array}$} \\
\hline
\end{tabular}

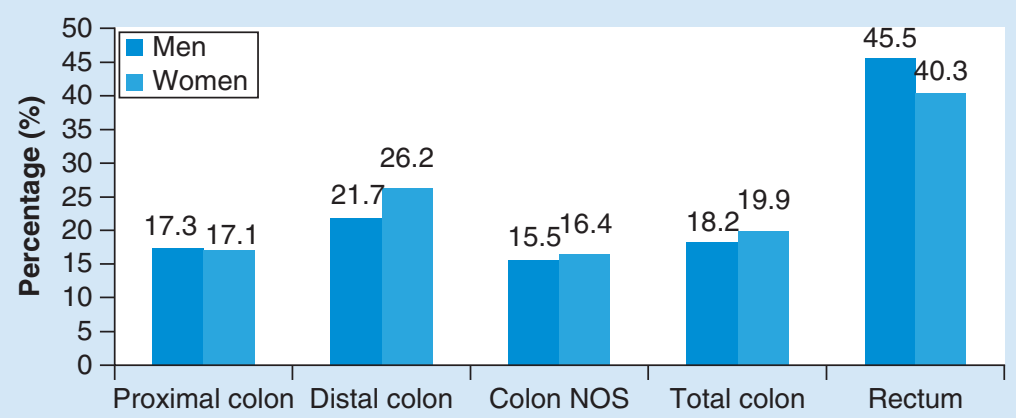

Figure 6. Proportion of cases by gender and subsite.

NOS: Not otherwise stated.

Table 3. Number and proportion of cases by gender, site of cancer and histological type.

\begin{tabular}{|c|c|c|c|c|c|c|}
\hline \multirow[t]{2}{*}{ Histological type } & \multicolumn{3}{|c|}{ Men, n (\%) } & \multicolumn{3}{|c|}{ Women, n (\%) } \\
\hline & Colon & Rectum & Colorectal & Colon & Rectum & Colorectal \\
\hline Adenocarcinoma & $445(86.1)$ & $371(86.7)$ & $816(86.3)$ & 477 (83.7) & $266(85.0)$ & $639(82.0)$ \\
\hline $\begin{array}{l}\text { Mucinous } \\
\text { adenocarcinoma }\end{array}$ & $22(4.3)$ & $16(3.7)$ & $38(4.0)$ & $29(5.1)$ & $22(7.0)$ & $51(6.5)$ \\
\hline Carcinoma NOS & $20(3.9)$ & $19(4.4)$ & $39(4.1)$ & $16(2.8)$ & $8(2.6)$ & $24(3.1)$ \\
\hline Sarcoma & $2(0.4)$ & $4(0.9)$ & $6(0.6)$ & $4(0.7)$ & $0(0.0)$ & $4(0.5)$ \\
\hline Malignant NOS & $28(5.4)$ & $18(4.2)$ & $46(4.9)$ & $44(7.7)$ & $17(5.4)$ & $61(7.8)$ \\
\hline
\end{tabular}

NOS: Not otherwise specified.

\section{Distribution by governorates}

The ASR varied widely by regions in northern Tunisia; highest rates were observed in Bizerte $(13.8 / 100,000)$, the district of Tunis $(12.7 / 100,000)$ and Nabeul $(12.3 / 100,000$ persons). Figure 7 shows that the discovery of the tumor at a local stage was higher in the governorates of Tunis and Bizerte. While the western region showed lowest rates (Figure 8). 


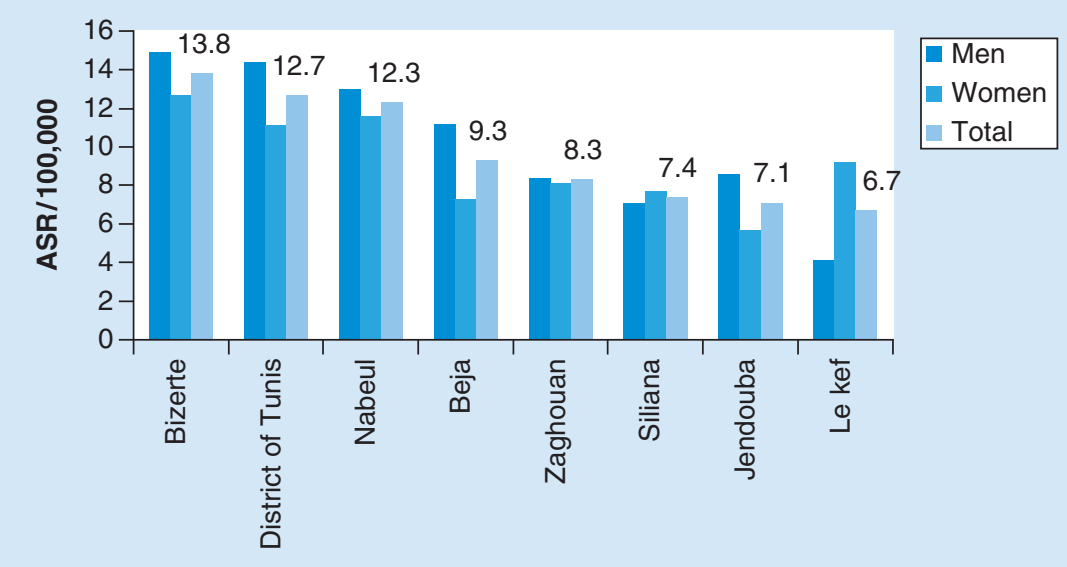

Figure 7. Distribution of age-standardized incidence rates (ASRs) by governorates.

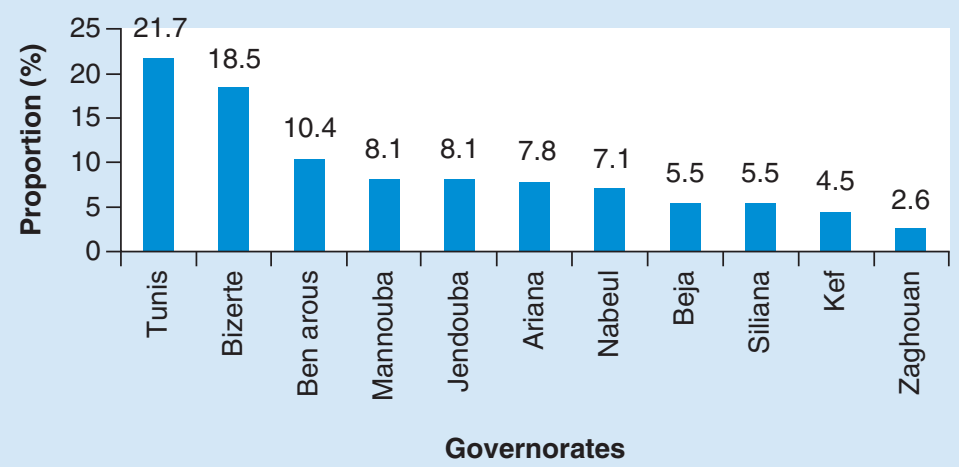

Figure 8. Percentage of local extension stage at diagnosis according to governorates.

\section{Discussion}

This study has highlighted an ASR of 12.4 cases/100,000 (13.6 against 11.1, respectively, in men and women) of CRC during the 2007-2009 period in the northern region of Tunisia. This incidence is very close to that reported by the registry of cancer of the Sousse region for the 2003-2007 period, which was 11.3 cases (12.6 for men and 10.1 for women) $[6,19,20]$. The ASR by site in the region of Sousse were also very close to rates reported in this study, which were respectively 7.0 and 5.9 in men and women for colon cancer against 5.6 and 4.2 for rectal one.

CRC is the third most common cancer worldwide, with 1.2 million new cases estimated by GLOBOCAN 2012 [15], with an average ASR of 17.2 cases/100,000.

The incidence rate of CRC varies widely between different regions of the world $[6,13,19]$. Countries with high incidence (>40/100,000 inhabitants), well above the rate observed in the northern region of Tunisia, are the USA, Canada, Australia, New Zealand and some parts of Europe (The Czech Republic and Slovakia); while low-incidence countries, with a relatively close rates to that reported by this study are essentially India, Egypt and central east of Africa $[4-6,13,15,22]$. The incidence trend is declining in developed countries, on the contrary of developing countries where, this trend is on the rise. In Tunisia, an increasing of CRC incidence was observed in central and north of Tunisia $[20,23]$.

The ASR in other Maghreb countries are also rather close to those reported in this work. Incidence rates were 10.5/100,000 (12 in men and nine in women) in Morocco (2006-2008 registry) [24] and 11/100,000 (8.7 in men and 13.4 in women) [25] in Algeria (2006). The comparison with middle east countries shows that the ASR of CRC 
in northern Tunisia is lower compared with those observed in Lebanon (19.1/100,000 [19.5-18.9]) [26], Qatar (18.4/100,000 [20.2-16.6]) and Jordan (17.3/100,000 [18.2-16.5]) [27]. While some countries such as Bahrain $(12.3 / 100,000$ [14.7-10]) [28] and Kuwait (12.7/100,000 [13.6-11.8]) [29] show almost similar incidence to our results. In contrast, incidence observed in this study were higher than those recorded in Iran in 2009 (8.5/100,000 [11.3-5.8]) [30] and in Egypt (5.4/100,000 [6-4.9]) [31].

The comparison with Asian countries shows a close level of incidence in Turkey with an ASR of 14/100,000 [32]. While rates in other countries in Asia are higher; thus in Korea and Japan where the ASR are, respectively, 36 and 35/100,000 [33-35].

These differences between countries could be explained mainly by nutrition behavior, practice of physical activity, obesity and also by screening activities $[10,14,36]$.

Tunisia is situated among countries with a middle-to-low rate of ASR CRC. This result should be accompanied by a study on the trend of this cancer which is known to be declining or stable in developed countries.

The present study showed that 60 years was the mean age at diagnosis in northern Tunisia that is slightly higher than that observed in other north-African countries such as Morocco and Algeria with an average age around 55 years [37-40]. The average age is much lower in Egypt and some African countries with, respectively, 50 and 47 years [31,41-43]. Otherwise, the average age is around 70 years in Westernized countries [44,45]. The young average age in the northern region of Tunisia, as well as in developing countries, could be explained by the young population structure in these regions $[29,46]$.

Patients over 50 years old accounted for $75 \%$, which is close to that observed in Morocco (75\%) and China $(72 \%)[38,40,47]$, but remains lower than Westernized countries where over $90 \%$ of CRCs occur in people over 50 years [5,48-50]. The proportion of patients under 40 years (9\%), observed in this study is higher compared with those observed in developed countries such as the USA and France, where CRC in young patients is very rare before 40 years and accounts for $1-4 \%[44,48,50]$. CRC in young patients is more common in Maghreb countries with a proportion of $11 \%$ in Morocco and much higher in the Middle East with $18 \%$ in Turkey and 38\% in Egypt [51-53]. CRC in young adults (under 40) is important to consider because of their poor prognosis and their family character. The fight against these cancers is based on family screening, genetic study by molecular biology and early diagnosis in case of predisposing factors [13,54,55].

This study showed that the incidence gradually increased with age, especially from 40 years with a greater increase after 50 years. A peak of incidence was observed between 60 and 74 which is later in developed countries and earlier in some Maghreb countries (between 50 and 60 years in Morocco) and Asia (between 50 and 59 years in China). The distribution of incidence by age is important because it guides the screening strategy and particularly the lower limit of age to be targeted by this intervention. Indeed, it is clear that for ages with low specific incidence rates (young adult) with generally poor prognosis and sometimes familial or genetic characteristics are not suitable for mass screening (the cost-effectiveness of screening would be reduced) [13,56-59].

Male gender is reported to be more concerned by CRC $[8,60]$. This was confirmed by our study where sex ratio was 1.2. This ratio remains stable for 15 years in Tunisia and is very close to that observed in other Maghreb and Middle-Eastern countries (around 1.1) [5,29,38,40]. Male predominance is obvious in Westernized countries between 1.5 and 1.7 [48,61], but also in central Africa, especially in Niger and Congo with respectively a gender ratio of 1.5 and $1.6[43,62]$. The male predominance in CRC reported in the literature is poorly understood; Wu et al. explain that by a more exposure to risk factors for this cancer between males [63].

Our study showed that the most affected sites were the rectum, distal and proximal colon with, respectively, 43, 24 and 17\%. Our results are consistent with those observed in China and Africa, where the most affected site is the rectum and the least reached one is proximal colon $[40,47,64]$. This is not the case in developed countries as in the USA and Canada, where the most affected site is the proximal colon followed by the rectum $[5,48,50,60,65]$.

Gender ratio also differs depending on the site [66]; for colon cancer, the gender ratio is around one with a slight male predominance that concord with the results of our study (gender ratio $=1.1$ ). However, for rectal cancer the male predominance is more obvious $[8,60,61,67]$ that also concord with our results and gender ratio was 1.3.

Regarding colon cancer, the relation between gender and proximal or distal sites varies between countries. In the present study, women predominance was observed in distal colon while in Western countries, it is the proximal. Some series speak about right to left shift, which mean an increase in cases in proximal colon against decreasing cases in distal colon, especially for women [68-70]. Which can be explained by the progress in diagnosis technology, so that proximal colon cancer can be more explored and diagnosed in developed countries. This was not the case in our study. 
According to the literature, the most common histological type is adenocarcinoma, the proportion reported in the present study was $84.4 \%$. This percentage concord with those observed in other Maghreb [71], Middle East and Asian countries (73.4\% in Niger, $82 \%$ in Morocco, $84.6 \%$ in Jordan). However, it is relatively lower than those of Western countries (94\% of cancers in Europe) [72].

This study showed that the highest rates were observed in the governorates of Bizerte, the District of Tunis and Nabeul with, respectively, $13.8,12.7$ and 12.3/100,000 that constitute the higher socioeconomic governorates in northern Tunisia; while the lowest incidence rates were recorded in the governorate of Kef $(6.7 / 100,000)$, Jendouba (7.1/100,000), Siliana (7.4/100,000) and Zaghouan (8.3/100,000). Several hypotheses could explain these differences; The first one is related to diagnostic facilities in governorates benefiting from best care [73]. In favor of this hypothesis, a higher proportion of cases diagnosed at a local stage of development of the tumor; in fact, this proportion was higher in the governorate of Tunis, followed by the governorate of Bizerte and Ben Arous. The lowest rates were observed in Siliana, Kef and especially in Zaghouan. The second assumption is related to different levels of exposure to major risk factors, including poor dietary behavior, lack of physical activity and obesity.

\section{Conclusion}

This study has shown that Tunisia is still situated among countries with a middle-to-low rate of ASR CRC. The mean age at diagnosis in northern Tunisia was 60 years and male gender was more concerned by CRC. The most affected subsites were respectively the rectum, distal then proximal colon. Commonly, adenocarcinoma was the most common histological type. Higher incidence in some governorates could be related to better access to health services in these governorates increasing the probability of CRC detection, and also to higher level of main colorectal risk factors. CRC screening should be strengthened in Tunisia to achieve a reduction of CRC incidence and mortality.

\section{Future perspective}

Promoting primary prevention of CRC risk factors, strengthening CRC screening and increasing public awareness are recommended to reduce CRC incidence and mortality in Tunisia.

Financial \& competing interests disclosure

The authors have no relevant affiliations or financial involvement with any organization or entity with a financial interest in or financial conflict with the subject matter or materials discussed in the manuscript. This includes employment, consultancies, honoraria, stock ownership or options, expert testimony, grants or patents received or pending, or royalties.

No writing assistance was utilized in the production of this manuscript.

\section{References}

1. Alwan A. Global status report on noncommunicable diseases 2010. WHO (2011). www.who.int/nmh/publications/ncd_report2010/en/

2. Boyle P, Langman J. ABC of colorectal cancer: epidemiology. Brit. J. Med. 321(7264), 805-808 (2000).

3. Ferlay J, Soerjomataram I, Dikshit R et al. Cancer incidence and mortality worldwide: sources, methods and major patterns in GLOBOCAN 2012. Int. J. Cancer 136(5), E359-E386 (2015).

4. Center MM, Jemal A, Smith RA, Ward E. Worldwide variations in colorectal cancer. CA Cancer J. Clin. 59(6), 366-378 (2009).

5. Haggar F, Boushey R. Colorectal cancer epidemiology: incidence, mortality, survival, and risk factors. Clin. Colon Rectal Surg. 22(4), 191-197 (2009).

6. Jemal A, Bray F, Center MM, Ferlay J, Ward E, Forman D. Global cancer statistics. CA Cancer J. Clin. 61(2), 69-90 (2011).

7. Jemal A, Center MM, DeSantis C, Ward EM. Global patterns of cancer incidence and mortality rates and trends. Cancer Epidemiol. Biomarkers Prev. 19(8), 1893-1907 (2010).

8. Siegel R, Desantis C, Jemal A. Colorectal cancer statistics, 2014. CA Cancer J. Clin. 64(2), 104-117 (2014).

9. Glade M. Food, Nutrition, Physical Activity and the Prevention of Cancer: A Global Perspective. American Institute for Cancer Research, Washington DC, USA (2007).

10. Johnson CM, Wei C, Ensor JE et al. Meta-analyses of colorectal cancer risk factors. Cancer Cause Control. 24(6), 1207-1222 (2013).

11. Marmot M, Atinmo T, Byers T et al. Food, Nutrition, Physical Activity, and the Prevention of Cancer: A Global Perspective. American Institute for Cancer Research, Washington DC, USA (2007).

12. Bishehsari F, Mahdavinia M, Vacca M, Malekzadeh R, Mariani-Costantini R. Epidemiological transition of colorectal cancer in developing countries: environmental factors, molecular pathways, and opportunities for prevention. World J. Gastroenterol. 20(20), 6055-6072 (2014). 
13. Kuipers EJ, Grady WM, Lieberman D et al. Colorectal cancer. Nature Rev. Dis. Primers 1, 15065 (2015).

14. Marley AR, Nan H. Epidemiology of colorectal cancer. Int. J. Mol. Epidemiol. Genet. 7(3), 105-114 (2016).

15. Ferlay J, Soerjomataram I, Ervik M et al. Estimated cancer incidence, mortality and prevalence worldwide in 2012. International Agency for Research on Cancer (2013). http://globocan.iarc.fr

16. Plan de lutte contre le cancer en Tunisie 2015-2019. Ministère de la santé, Tunis (2015). www.iccp-portal.org/system/files/plans/Plan_pour_la_lutte_contre_le_cancer_2015-2019_Tunisie.pdf

17. Ben Abdallah M, Zehani S, Hizem Ben Ayoub W, Hsairi M, Achour N. Registre des Cancers NORD-TUNISIE Données 2004-2006. Institut Salah AZAIEZ. Tunis (2012). www.insp.rns.tn/doc/cancer/cancer17.pdf

18. Institut National de la Statistique: Ministere du Developpement de l'Investissement et de la Cooperation Internationale. www.ins.nat.tn/

19. Forman D, Bray F, Brewster DH et al. Cancer Incidence in Five Continents (Volume X). IARC, Lyon, France (2016).

20. Missaoui N, Trabelsi A, Parkin DM et al. Trends in the incidence of cancer in the Sousse region, Tunisia, 1993-2006. Int. J. Cancer 127(11), 2669-2677 (2010).

21. Missaouia N, Jaidaine L, Ben Abdelkader A et al. Clinicopathological patterns of colorectal cancer in Tunisia. Asian Pac. J. Cancer Prev. 11(6), 1719-1722 (2010).

22. Center MM, Jemal A, Ward E. International trends in colorectal cancer incidence rates. Cancer Epidemiol. Biomarkers Prev. 48(6), 1688-1694 (2009).

23. Khiari H, Ben Ayoub HW, Ben Khadhra H, Hsairi M. Colorectal Cancer incidence trend and projections in Tunisia (1994-2024). Asian Pac. J. Cancer Prev. 18(10), 2733-2739 (2017).

24. Tazi MA, Er-Raki A, Benjaafar N. Cancer incidence in Rabat, Morocco: 2006-2008. Ecancermedicalscience 7, 338 (2013). www.ncbi.nlm.nih.gov/pmc/articles/PMC3737118/

25. Cherif H, Bidoli E, Birri S et al. Cancer estimation of incidence and survival in Algeria 2014. J. Cancer Res. Ther. 3(9), 100-104 (2015).

26. Shamseddine A, Saleh A, Charafeddine $M$ et al. Cancer trends in Lebanon: a review of incidence rates for the period of 2003-2008 and projections until 2018. Popul. Health Metr. 12(1), 1-8 (2014).

27. Tarawneh M, Nimri O, Arkoob K, Zaghal MA. Cancer Incidence in Jordan 2009. Ministry of Health, Jordan (2009).

28. Alsayyad J, Hamadeh R. Cancer incidence among the Bahraini population: a five-year (1998-2002) experience. Hematol. Cell Ther. 1(3), 175-182 (2008).

29. Salim EI, Moore MA, Al-Lawati JA et al. Cancer epidemiology and control in the Arab world - past, present and future. Asian Pac. J. Cancer Prev. 10(1), 3-16 (2009).

30. Rezaianzadeh A, Safarpour AR, Marzban M, Mohaghegh A. A systematic review over the incidence of colorectal cancer in Iran. Ann. Colorectal Res. 3(1), e25724 (2015).

31. Ibrahim AS, Khaled HM, Mikhail NN, Baraka H, Kamel H. Cancer incidence in Egypt: results of the national population-based cancer registry program. J. Cancer Epidemiol. 2014, 437971 (2014).

32. Eser S, Yakut C, Özdemir R et al. Cancer incidence rates in Turkey in 2006: a detailed registry based estimation. Asian Pac. J. Cancer P. 11(6), 1731-1739 (2009).

33. Shin A, Jung KW, Won YJ. Colorectal cancer mortality in Hong Kong of China, Japan, South Korea, and Singapore. World J. Gastroenterol. 19(7), 979-983 (2013).

34. Yee YK, Tan VP, Chan P, Hung IF, Pang R, Wong BC. Epidemiology of colorectal cancer in Asia. J. Gastroenterol. Hepatol. 24(12), 1810-1816 (2009).

35. Yiu HY, Whittemore AS, Shibata A. Increasing colorectal cancer incidence rates in Japan. Int. J. Cancer 109(5), 777-781 (2004).

36. Bishehsari F, Mahdavinia M, Vacca M, Malekzadeh R, Mariani-Costantini R. Epidemiological transition of colorectal cancer in developing countries: environmental factors, molecular pathways, and opportunities for prevention. World J. Gastroenterol. 20(20), 6055-6072 (2014).

37. Arfaoui A, Quyou A, Soulaymani A, Habib F, Choulli M. Cancer colorectal au Maroc: etude rétrospective dans un centre d'oncologie à Rabat. Maghreb Med. 156, 37-43 (2008).

38. Benider A, Harif M, Karkouri M, Quessar A, Sahraoui S, Sqali S. Registre des cancers de la région du Grand Casablanca, Année 2005-2007. Association Lalla Salma, Maroc (2012).

39. Hamdi Cherif M, Serraino D, Mahnane A et al. Time trends of cancer incidence in Setif, Algeria, 1986-2010: an observational study. BMC Cancer 14, 637 (2014).

40. Mallem D. Les cancers colorectaux dans les wilayas de batna etude epidemiologique clinique et therapeutique [sciences médicales]. Universite de Batna (2010). http://eprints.univ-batna2.dz/id/eprint/529

41. Diallo Owono F, Nguema Mve R, Ibaba J, Mihindou C, Ondo N'dong F. Aspects épidemiologiques et diagnostiques des cancers colorectaux à Libreville (Gabon). Med. Trop. 71(6), 605-607 (2011). 
42. Graham A, Adeloye D, Grant L, Theodoratou E, Campbell H. Estimating the incidence of colorectal cancer in sub-Saharan Africa: a systematic analysis. J. Glob. Health 2(2), 020404 (2012).

43. Salamatou MG, Hinde H, Abdelmadjid S, Ali Q, Harouna MZ, Hassan N. Les cancers digestifs au Niger. Fréquence relative sur une etude rétrospective de 1992 a 2009. Eur. Sci. J. 10(9), 1493-1497 (2014).

44. Bruchez F, Levi F, Levi F, Bulliard J-L. Incidence des cancers et des polypes colorectaux dans le canton de Vaud 1983-2007. Rev. Med. Suisse 7, 2247-2251 (2009).

45. Fournet J, Dhumeaux D. Le Livre Blanc de l'Hépato-Gastroentérologie. Masson, Paris, France (2001).

46. Haggar FA, Boushey RP. Colorectal cancer epidemiology: incidence, mortality, survival, and risk factors. Clin. Colon Rectal Surg. 22(4), 191 (2009).

47. Cai B, Wang M-Y, Liao K et al. Distribution characteristics of 3369 Chinese colorectal cancer patients for gender, age, location and tumor size during colonoscopy. Asian Pac. J. Cancer Prev. 15(20), 8951-8955 (2014).

48. Bouvier AM. Epidémiologie descriptive du cancer colorectal en France. Inserm, France (2009).

49. Faivre J. Epidémiologie et prévention du cancer colorectal. Springer Science \& Business Media, France (2001).

50. Howlader N, Noone A, Krapcho M et al. SEER Cancer Statistics Review, 1975-2012. Bethesda, MD, USA. http://seer.cancer.gov/csr/1975_2012/

51. Abou-Zeid AA, Khafagy W, Marzouk DM, Alaa A, Mostafa I, Ela MA. Colorectal cancer in Egypt. Dis. Colon Rectum 45(9), 1255-1260 (2002).

52. Alici S, Aykan NF, Sakar B, Bulutlar G, Kaytan E, Topuz E. Colorectal cancer in young patients: characteristics and outcome. Tohoku J. Exp. Med. 199(2), 85-93 (2003).

53. Gado A, Ebeid B, Abdelmohsen A, Axon A. Colorectal cancer in Egypt is commoner in young people: is this cause for alarm? Alexandria Med. J. 50(3), 197-201 (2014).

54. Fadlouallah M, Benzzoubeir N, Errabih I et al. Colorectal carcinoma in patients younger than 40 years of age: about 40 cases. J. Afr. Cancer 2(2), 112-115 (2010).

55. Colussi D, Brandi G, Bazzoli F, Ricciardiello L. Molecular pathways involved in colorectal cancer: implications for disease behavior and prevention. Int. J. Mol. Sci. 14(8), 16365 (2013).

56. Campos FG. Colorectal cancer in young adults: a difficult challenge. World J. Gastroenterol. 23(28), 5041-5044 (2017).

57. Bedikian AY, Kantarjian H, Nelson RS, Stroehlein JR, Bodey GP. Colorectal cancer in young adults. Southern Med. J. 74(8), 920-924 (1981).

58. Lansdorp-Vogelaar I, Knudsen AB, Brenner H. Cost-effectiveness of colorectal cancer screening. Epidemiol. Rev. 33(1), 88-100 (2011).

59. Deen KI, Silva H, Deen R, Chandrasinghe PC. Colorectal cancer in the young, many questions, few answers. World J. Gastrointest. Oncol. 8(6), 481-488 (2016).

60. Devesa SS, Chow WH. Variation in colorectal cancer incidence in the United States by subsite of origin. Cancer 71(12), 3819-3826 (1993).

61. Perron L, Vandal N. L'incidence du cancer colorectal selon le sexe et le site anatomique. Institut Nationale de Santé Publique au Québec (2011). www.inspq.qc.ca/pdf/publications/1200_ApercuCancerQcEvolColorectalSexeSiteAnatom.pdf

62. Peko J, Ibara J, Dangou J, Gombe Mbalawa C. Profil histo-epidemiologique de 375 cancers digestifs primitifs au CHU de Brazzaville. Med. Trop. 64(2), 163-170 (2004).

63. Wu X, Cokkinides V, Chen VW et al. Associations of subsite-specific colorectal cancer incidence rates and stage of disease at diagnosis with county-level poverty, by race and sex. Cancer 107(S5), 1121-1127 (2006).

64. Zhou Q, Li K, Lin GZ et al. Incidence trends and age distribution of colorectal cancer by subsite in Guangzhou, 2000-2011. Chin. J. Cancer 49(2), 142-146 (2015).

65. Rim SH, Seeff L, Ahmed F, King JB, Coughlin SS. Colorectal cancer incidence in the United States, 1999-2004. Cancer 115(9), 1967-1976 (2009).

66. Kim SE, Paik HY, Yoon H, Lee JE, Kim N, Sung MK. Sex- and gender-specific disparities in colorectal cancer risk. World J. Gastroenterol. 21(17), 5167-5175 (2015).

67. Gatta G, Ciccolallo L, Capocaccia R et al. Differences in colorectal cancer survival between European and US populations: the importance of sub-site and morphology. Eur. J. Cancer 39(15), 2214-2222 (2003).

68. Gao R-N, Neutel CI, Wai E. Gender differences in colorectal cancer incidence, mortality, hospitalizations and surgical procedures in Canada. J. Public Health 30(2), 194-201 (2008).

69. Neutel CI, Gao R-N, Wai E, Gaudette LA. Trends in in-patient hospital utilization and surgical procedures for breast, prostate, lung and colorectal cancers in Canada. Cancer Cause Control. 16(10), 1261-1270 (2005).

70. Saltzstein SL, Behling CA. Age and time as factors in the left-to-right shift of the subsite of colorectal adenocarcinoma: a study of 213,383 cases from the California Cancer Registry. J. Clin. Gastroenterol. 41(2), 173-177 (2007). 
71. El Housse H, Ajbara W, Amsaguine S et al. Profils épidémiologique et anatomoclinique d'une population marocaine atteinte de cancer colorectal. J. Afr. Cancer 7(2), 95-99 (2015).

72. Puddu M. Cancer colorectal: état des connaissances et données disponibles pour le développement d'une politique de santé en Belgique. Institut scientifique de la santé publique, Section d'epidémiologie (2006). www.wiv-isp.be/epidemio/epifr/crospfr/colorectal_fr.pdf

73. Secco GB, Fardelli R, Campora E et al. Primary mucinous adenocarcinomas and signet-ring cell carcinomas of colon and rectum. Oncol. 51(1), 30-34 (1994). 